$0.2 \%$ in femoral procedures, a very important difference $(\mathrm{p}<$ 0.001 ). Heparinisation did not reduce the risk either of thrombosis or of embolisation.

The increased risk of death found in the American collaborative study to be associated with the brachial artery technique of arteriography was an unexpected finding. Comparison of possible risk factors in the patients studied by the two techniques showed that they were comparable in every respect (apart from peripheral vascular disease, which was not found to be a significant risk factor for postarteriography death). Furthermore, in every patient who died after a brachial artery procedure a Sones-type catheter rather than a preshaped catheter had been used, so that the deaths could not be attributed to abandonment of the "classical" Sones technique.

Nevertheless, the overall risk of coronary arteriography was reassuringly low-only two in 1000-and deaths were confined to patients with the most severe disease. These patients who died were living at high risk; their doctors would not have been surprised by sudden death or myocardial infarction had it occurred at any other time than the 48 hours after coronary arteriography. The existence of advanced coronary artery disease or of poor left ventricular function is usually clinically predictable and the indications for investigation of such patients tend to be strong: severe disability and a poor prognosis. Critics who castigate the "need to know" indication for coronary arteriography should, perhaps, recognise that at least it carries almost no risk to life and a minimal risk of local arterial complications if the femoral approach is used.
1 Sones FM, Shirey EK. Cine coronary arteriography. Mod Concepts Cardiovasc Dis $1962 ; 31: 735-8$

${ }^{2}$ Judkins MP. Selective coronary arteriography part I: a percutaneous transfemoral technic. Radiology 1967;89:815-24.

${ }^{3}$ Ross RS, Gorlin R. Coronary arteriography. Circulation 1968;38, suppl 3: 67-73.

4 Braunwald E. Deaths related to cardiac catheterization. Circulation 1968; 38, suppl $3: 17-26$.

5 Cohen MV, Cohen PF, Herman MV, Gorlin R. Diagnosis and prognosis of main left coronary artery obstruction. Circulation $1972 ; 45$, suppl 1 : 57-65.

${ }^{6}$ Petch MC, Sutton R, Jefferson KE. Safety of coronary arteriography. Br Heart $\mathcal{f} 1973 ; 35: 377-80$.

${ }^{7}$ Emanuel R. Coronary arteriography. Br Heart $\mathcal{f} 1975$;37:229-30.

${ }^{8}$ Pridie RB, Booth E, Fawzey E, et al. Coronary angiography. Review of 1500 consecutive cases. Br Heart $\mathcal{F}$ 1976;38:1200-3.

${ }^{9}$ Green GS, McKinnon CM, Rosch J, Judkins MP. Complications of selective percutaneous transfemoral coronary arteriography and their prevention. A review of 445 consecutive examinations. Circulation $1972 ; 45: 552-7$

${ }^{10}$ Lebowitz WB, Lucia W. Complications of selective percutaneous transfemoral coronary arteriography. Radiology 1975;116:545-7.

11 Bristow JD, Burchell HB, Campbell RW, et al. Report of the Ad Hoc Committee on the Indications for Coronary Arteriography. Circulation $1977 ; 55: 969-74 A$.

12 Schroeder SA. The complications of coronary arteriography: a problem that won't go away. Am Heart $\mathcal{F} 1980 ; 99: 139-41$.

${ }^{13}$ Davis K, Kennedy JW, Kemp HG, Judkins MP, Gosselin AJ, Killip T. Complications of coronary arteriography from the Collaborative Study of Coronary Artery Surgery (CASS). Circulation 1979;59:1105-11.

14 Lavine P, Kimbiris D, Segal BL, Linhart JW. Left main coronary artery disease: clinical, arteriographic and hemodynamic appraisal. $A m \mathcal{J}$ Cardiol 1972;30:791-6.

15 Bourassa MG, Noble J. Complication rate of coronary arteriography. A review of 5250 cases studied by a percutaneous femoral technique. Circulation 1976;53:106-14.

16 Abrams HL, Adams DF. The complications of coronary arteriography. Circulation 1975;52, suppl 2:27.

\title{
In pursuit of excellence
}

In September 1880 two American pharmacists working in London established a partnership which has endured for 100 years because of a unique combination of commercial enterprise and innovative research and development. ${ }^{1}$ Silas Burroughs (1846-95) was an extravert with progressive political ideas and a technical skill in promoting new products; he died at the height of his career. Henry Wellcome (1853-1936) came of frontier stock and was reserved and religious, but he had a driving ambition for perfection. Burroughs Wellcome pioneered enlightened employment in its factory at Dartford, high-quality pharmaceutical products, and an interest in the health of developing countries. The tabloid trade mark, registered in 1884, soon became known world wide as a symbol of reliability. Two popular laxatives were known as Livingstone Rouser and Forced March. By 1924 there were nine associated companies in different countries, and these were amalgamated, together with the various research institutes and museums, into the Wellcome Foundation Limited. A quarter of a million pounds was spent on building the Wellcome Research Institution in Euston Road, which was opened in 1932 to house Wellcome's historical medical collections.

Between the wars the company's fortunes were somewhat depressed, and when Sir Henry Wellcome died in 1936 there was a shortage of money to set up the Wellcome Trust, a grandiose scheme on which he had been working for many years. The skill of the trustees and successful wartime contracts overcame these temporary difficulties, and by 1979 the trust had spent $£ 56$ million on medical and scientific research. It is now the largest of the British charities which support research, and the range of its activities has been extraordinarily wide. It began by financing the building of laboratories and the purchase of expensive technical equipment and then moved into extensive research in veterinary and tropical medicine. Later still, senior clinical research fellowships, travel grants, and exchange fellowships were established, and topics as different as mental health and the history of medicine were supported with money and-equally important-ideas.

Finance came from a drug company which was imbued with its founders' desire to relieve suffering and to promote excellence. Research was carried out by able men-at first into plant alkaloids and then during the first world war into synthetic drugs; at the same time others were solving the practical problems of marketing and distribution. A meeting with the explorer H M Stanley, for example, led to the production of medicine chests for travellers, and a floating laboratory was designed for use on the Nile. The impressive achievements of the Burroughs Wellcome laboratories both here and in the United States include diphtheria antitoxin, the first sulphone derivatives, large-scale manufacture of insulin a year after its discovery, the isolation and purification of digoxin exactly 50 years ago, many products for veterinary and tropical medicine, the early antimetabolites, allopurinol, Septrin, and now interferon. Some of the most eminent scientists have worked for the company, and one of them, Sir Henry Dale, was awarded the Nobel prize for work on the chemical transmission of nervous stimuli, which stemmed from early research on ergot alkaloids. The first physiological research laboratories set up in 1894 had a team of 12 , of whom no fewer than seven became Fellows of the Royal Society.

Burroughs Wellcome now has 65 subsidiary and associated companies employing 18000 people, with world-wide sales of $£ 400$ million a year. The current research budget is $£ 40$ 
million, and profits are used to support the trust. "If you have an idea, I'll give you the freedom to develop it," said Henry Wellcome. The company can be proud that it has done just that, and, in these days when drug firms are so often portrayed as villains, it is appropriate that we should offer Burroughs Wellcome our congratulations.

1 In search of excellence: one hundred years Wellcome. 1880-1980. London: Wellcome Foundation Limited, 1980.

\section{High-risk groups and cervical cancer}

Screening for cervical cancer continues to cause controversy despite its long history. In many ways the test matches up to the ideal criteria for screening proposed by Wilson and Jungner ${ }^{1}$-in particular, cervical cancer has a recognisable latent stage and treatment is effective. Since, however, no control trial was done early on, how best to apply the procedure has been left to a futile debate between "evangelists" and "snails." 2 There is just enough in the jigsaw of information to make withdrawal of screening unethical, but insufficient for unassailable recommendations. The arguments arise principally because of the failure to distinguish decision making for individual patients (by the clinical evangelist) from decision making for communities (by the policy snails).

The decisions on the most effective use of health service resources for the benefit of the community are usually made on inadequate data. The basic principle, however, is that the policy should, firstly, benefit the community as a whole and then, secondly, the individual, implying that the goal for screening will most often be less than $100 \%$ detection. How far less and at what cost in illness is a matter of judgment.

The size of the benefit for the community from screening for cervical cancer may be assessed from mortality. In 1963, for example, 2465. women of all ages died from cervical cancer; 2153 died in 1978. The total death rate since 1970 has shown a modest downward trend. There has been a steady reduction in mortality for women aged 45-54 and, until 1976, for women aged 35-44. In part these declines may have been a result of screening; but, with no relaxation of screening, the rates in 1977 and 1978 for the younger women rose to the 1970 levels. Mortality in women aged 25-34 has risen since 1970, but the actual numbers of deaths per year have been small: about 35 during the '60s, rising to 93 in 1978 . Between 1970 and 1976 the number of deaths in the under-25-year-olds rose from five to nine a year but the total dropped to two and one in the next two years.

The distribution of the screening effort in England, even allowing for lead time, has failed to reflect the magnitude of mortality in each age group. In 1977 (and previous years were similar) 2.5 million cytological tests ${ }^{3}$ were carried out, of which $24 \%$ were for women under the age of 25 , in whom less than $0.5 \%$ of deaths occurred, and $33 \%$ of tests were on women aged 25-34, in whom less than $15 \%$ of deaths occurred. If resources are restricted, is this a reasonable way of spending them?

Expenditure could clearly be reduced by screening fewer women and selecting only those at high risk. Hakama and his colleagues $^{4}$ have examined this possibility using data from the Finnish mass screening system. All Finnish women at an age of high risk (roughly between 30 and 54) are invited to screening every five years. On the first visit information is collected on the known risk factors for cervical cancer. The group of women with bleeding or with class II-V smears without positive histological results were found to make up less than $10 \%$ of the responders but accounted subsequently for 20 $40 \%$ of the invasive carcinomas. Hakama et al suggested that these women might be screened selectively more often than the standard interval of five years, a recommendation which would increase the cost of the programme-in England it might mean roughly 30000 extra smears each year if the selective screening were done every two and a half years instead of every five.

An alternative is to set an arbitrary target for detection. At the community level this might be $90 \%$ of all carcinomas. Again, Hakama et $a l^{5}$ have examined the Finnish data, to see whether a high-risk group could be defined which would substantially reduce the size of the group requiring screening. By applying statistical scoring methods to data on the levels of each woman's risk factors at first screening they found that about half of those with all non-normal lesions-and of those with frankly invasive carcinoma or with dysplasia gravis or carcinoma in situ-were in the $15 \%$ of the screened population with the highest scores. Important risk factors were age, parity, cytological diagnosis, and coital and postmenopausal bleeding. Nevertheless, not until the high-risk group was defined as the $70 \%$ of the whole screened population with the highest risk scores did it include $90 \%$ of cases.

The size of the high-risk group could be substantially reduced while still maintaining a $90 \%$ detection rate only if the risk factors were associated with relative risk of 15 or more, a very unlikely event. The conclusion must be that the concept of high-risk screening for cervical cancer does not seem valid, partly because of the penalty paid in missed cases and partly because of the effort required to determine who should be excluded.

$\mathrm{Knox}^{6}$ has calculated the frequency of screening needed to detect cervical cancer before it becomes inoperable. Making a number of assumptions, including the length of time a detectable lesion takes to become inoperable and that the cytology service could handle no more smears than currently, he then showed that by carrying out the first smear at age 35 and repeating the test roughly every five years until 80 years of age $77 \%$ of all deaths might be prevented.

Given the mortality pattern, the experience of screening systems, the application of our limited knowledge of the natural history of cervical cancer to models for the delivery of health services, community restraint and clinical demands might best be balanced by the recommendations published three years ago in the $B M Y .{ }^{7}$ Screening should begin at 25 for women presenting for contraception, pregnancy, or venereal disease, or at 30 if they were sexually active and had not been tested. The interval between smears should be five years (three years after 35 if resources permit); and screening could cease at 70 . If those recommendations were applied to every eligible woman mortality ought to decline by well over half. At present too much effort is spent in trying to detect cervical cancer in too young an age group where, even with $100 \%$ coverage and effectiveness, fewer than 10 of over 2000 deaths would be prevented.

1 Wilson JMG, Jungner G. Principles and practice of screening for disease. Geneva: World Health Organisation, 1968. (Public Health Paper No Geneva: World Health Organisation, 1968. (Public Health Paper No 34.)

2 Sackett DL, Holland WW. Controversy in the detection of disease. Lancet 1975 ;ii:357-9.

${ }^{3}$ Department of Health and Social Security. Health and personal social services statistics for England, 1978. London: HMSO, 1978. 